\title{
Una época de cambios: la industria textil argentina entre dos crisis, 1914-1933*
}

CLAUDIO BELINI**

Resumo: Este artigo analisa as mudanças acontecidas na indústria têxtil argentina, entre a Primeira Guerra Mundial e a Grande Depressão. Argumenta-se que durante a década de 1920 ocorreu um avanço na substituição das importações, liderado pela indústria lanífera, pela fabricação de tecidos de malha e de fibra sintética. Nesse sentido, o artigo examina os fatores que impulsionaram essas transformações.

Abstract: This article analyzes the changes that took place in the Argentine textile industry between the outbreak of the First World War and the Great Depression. It is argued that during the decade of 1920 took place an advance in the substitution of imports led by wool industry, knit goods and rayon fabrics. The article examines the factors that impelled these transformations.

Palavras-chave: Industria textil. Argentina. Entre-guerras.

Key words: Textile industry. Argentina. Interwar years.

\section{Introducción}

Una de las particularidades del crecimiento industrial argentino de la primera mitad del siglo XX fue el relativo rezago de la industria textil. A comienzos del siglo, la Argentina contaba con un mercado interno importante, un comercio exportador creciente y un ingreso per cápita relativamente alto. Además, el país era uno de los principales exportadores mundiales de lana y tenía áreas

* Este artículo contó en el apoyo del FONCYT/ANPCYT en el marco del proyecto PICT 13934.

* Investigador asistente del Consejo Nacional de Investigaciones Científicas y Tecnológicas (CONICET) con sede en el Programa de Estudios de Historia Económica y Social Americana (PEHESA), Instituto Ravignani, Universidad de Buenos Aires. E-mail: cfbelini@fibertel.com.ar

Estudos Ibero-Americanos, PUCRS, v. XXXIV, n. 2, p. 31-48, dezembro 2008 
ecológicamente aptas para la expansión del cultivo algodonero. A pesar de estas ventajas, la industria local sólo abastecía una parte menor de la demanda interna de textiles. En este sentido, la economía argentina mostraba claros signos de atraso en comparación con el Brasil y México. ${ }^{1}$ Estas paradojas han sido motivo de discusiones en la historiografía sin que se haya arribado a un acuerdo. Por un lado, autores influenciados por el estructuralismo y la tradición marxista han sostenido que el subdesarrollo de la rama se debió al predominio del librecambio y a la dependencia económica que resultaba de la relación especial entre la economía argentina y la británica. ${ }^{2}$ Por otro parte, otra corriente interpretativa, donde es claro el influjo ejercido por la economía neoclásica y el neoinstitucionalismo, ha rechazado la hipótesis según la cual las políticas públicas, y en especial la tarifa aduanera, habría constituido un factor de peso en ese retraso. Por el contrario, estos autores han puesto el acento sobre las desventajas derivadas de la reducida expansión del cultivo algodonero con anterioridad a $1920 .^{3}$

El objetivo de este artículo es analizar un período clave en la historia de la industria textil que comprende la década de 1920 y los primeros años de la Gran Depresión. La hipótesis general es que durante ese período se asistió a cambios importantes en la industria textil. Si bien es cierto que, como ha afirmado Petrecolla, la aceleración del crecimiento de la industria algodonera se dio principalmente como consecuencia de los efectos generados por la crisis internacional de 1929, en el decenio previo habían comenzado a darse algunas transformaciones en la rama textil, especialmente en la industria de la seda artificial y en las tejedurías de punto. Pese a su importancia, estos cambios han pasado desapercibidos;

1 Bulmer Thomas, Víctor. The Economic History of Latin America since independence. Cambridge: Cambridge University Press, 1994, p. 136-137; Korol, Juan Carlos y Tandeter, Enrique. Historia Económica de América Latina. Problemas y procesos. Buenos Aires: Fondo de Cultura Económica, 2000, p. 100-101.

2 Di Tella, Guido y Zymelman, Miguel. Las etapas del desarrollo económico argentino. Buenos Aires: Eudeba, 1967; Dorfman, Adolfo. Historia de la industria argentina. Buenos Aires: Solar, 1970; Colman, Oscar. La industria textil argentina y la reconversión extensiva del sector industrial argentino, 1930-1943. Ciclos, n. 2, p. 123-155, 1992; y, con algunas diferencias, Schvarzer, Jorge. La industria que supimos conseguir. Buenos Aires: Planeta, 1996.

3 Petrecolla, Alberto. Prices, import substitution and investment in the Argentine textile industry. Tesis de Doctorado, University of Columbia, 1968; Díaz Alejandro, Carlos. Ensayos sobre la historia económica argentina. Buenos Aires: Amorrortu, 1975; y Cortés Conde, Roberto. La economía argentina en el largo plazo. Buenos Aires: Sudamericana, 1997. 
opacados, en gran medida, por el rol predominante que tenía el consumo de artículos de algodón. ${ }^{4}$

En este artículo sostenemos que aún antes de la Gran Depresión se observaron progresos en la sustitución de importaciones. Los factores que impulsaron este proceso y su cronología son diferentes según la subrama que se analice; inicialmente, la industria lanera, que era la que reconocía un origen más antiguo en Argentina, tomó la delantera. Desde mediados de los años veinte, se acentuó la fabricación de tejidos de seda artificial que, si bien constituían una porción menor del consumo interno, alcanzó a satisfacer poco más del $50 \%$ de la demanda interna con anterioridad a 1929. En este caso, el crecimiento industrial se vio motorizado por los cambios en los procesos de producción a escala internacional y, paradójicamente, por la protección ofrecida por una tarifa aduanera anticuada, que sólo contemplaba a los artículos de seda natural. Finalmente, la industria algodonera se benefició, hasta mediados de la década de 1920, de la expansión de los cultivos de algodón en el nordeste del país, de manera tal que inició un tímido proceso de sustitución de importaciones. En este caso, como ha argumentado Petrecolla, la sustitución de importaciones se aceleró a partir del estímulo ofrecido por la crisis de 1929.

La primera parte de este artículo analiza la estructura de la industria en 1914 y resume brevemente las principales líneas de su desarrollo anterior. En la segunda, se estudian los principales instrumentos de política económica que afectaron el desempeño de la industria. Por último, la tercera parte analiza los cambios producidos durante la década de 1920 en tres subramas: lana, algodón y seda artificial.

\section{La industria textil en $\mathbf{1 9 1 4}$}

En la literatura sobre el tema existe consenso en el retraso argentino en desarrollar su industria textil. Todavía en 1923, una encuesta oficial determinó que el consumo de textiles era abastecido en un $73 \%$ por las importaciones. Los textiles, junto con los productos de acero, constituyeron entre la mitad y un tercio del total de las importaciones. ${ }^{5}$

4 El tema remite a una mirada menos "olímpica" del proceso de industrialización y más atenta a los cambios previos a la crisis de 1930. El estudio clásico es el de Villanueva, Javier. El origen de la industrialización argentina. Desarrollo Económico, n. 47, Buenos Aires, p. 451-476, 1972.

5 Dorfman, op. cit. p. 38; Díaz Alejandro, op. cit., p. 29. 
El retraso de la industria textil quedó evidenciado en las cifras ofrecidas por el Censo Nacional de 1914. Ese año la rama representó una quinta parte de los establecimientos y del personal empleado en la industria manufacturera, pero sólo un décimo de los capitales invertidos y una séptima parte del valor de la producción. Como se observa en el Cuadro 1, las tejedurías de punto y las de lana eran las actividades más desarrolladas en términos de inversiones, personal empleado y fuerza motriz instalada por obrero. En cambio, la producción de hilados mostraba un atraso importante; sólo existían tres hilanderías de algodón que estaban paralizadas, y en la rama lanera, una sola hilandería mecanizada producía para las tejedurías independientes. El censo también reveló la perduración de actividades tradicionales como 1.500 artesanos hilanderos en Salta y poco más de 700 tejedores domésticos en Salta y Catamarca. ${ }^{6}$

\section{CUADRO 1}

Número de establecimientos, capital invertido, valor de producción, fuerza motriz instalada y personal empleado en la industria textil argentina en 1914 (en pesos corrientes)

\begin{tabular}{|l|c|c|c|c|c|c|}
\hline \multicolumn{1}{|c|}{ Actividad } & Plantas & Capital & $\begin{array}{c}\text { Valor de } \\
\text { producción }\end{array}$ & $\begin{array}{c}\text { Fuerza } \\
\text { Motriz } \\
\text { HP }\end{array}$ & Personal & $\begin{array}{c}\text { Fuerza } \\
\text { motriz por } \\
\text { empleado }\end{array}$ \\
\hline $\begin{array}{l}\text { Hilanderías de } \\
\text { algodón }\end{array}$ & 3 & 835.000 & 15.000 & 194 & 6 & 32 \\
\hline $\begin{array}{l}\text { Hilanderías de } \\
\text { lana }\end{array}$ & 1.501 & 1.090 .000 & 705.000 & 300 & 1.682 & 0,2 \\
\hline $\begin{array}{l}\text { Tejedurías de } \\
\text { lana con o sin } \\
\text { hilandería }\end{array}$ & 16 & 7.429 .090 & 8.345 .698 & 3.038 & 2.721 & 1,1 \\
\hline $\begin{array}{l}\text { Tejedurías de } \\
\text { punto }\end{array}$ & 55 & 7.917 .240 & 12.046 .486 & 2.549 & 4.382 & 0,6 \\
\hline $\begin{array}{l}\text { Tejedurías de } \\
\text { algodón }\end{array}$ & 9 & 2.095 .475 & 3.037 .448 & 1.000 & 940 & 1,1 \\
\hline $\begin{array}{l}\text { Tejedurías de } \\
\text { hilo mezcla }\end{array}$ & 1 & 4.100 .000 & 1.800 .000 & 300 & 341 & 0,9 \\
\hline $\begin{array}{l}\text { Fábrica de } \\
\text { sombreros }\end{array}$ & 81 & 5.987 .250 & 7.829 .278 & 1.273 & 2160 & 0,6 \\
\hline $\begin{array}{l}\text { Tejeduría } \\
\text { doméstica }\end{array}$ & 715 & 110.214 & 196.665 & - & 2.112 & - \\
\hline Total & 2.448 & 29.564 .269 & 29.973 .242 & 9.316 & 15.305 & 0.6 \\
\hline
\end{tabular}

FUENTE: elaboración propia en base a Tercer Censo Nacional, op. cit.

6 El ingeniero Eusebio García estimó que el número de tejedores artesanos era mucho mayor debido a que en provincias como Santiago del Estero no se habían completado las cédulas censales. Tercer Censo Nacional. Año 1914. Buenos Aires: Rosso y Cía, vol. VII, p. 82. 
El atraso de la industria textil estaba relacionado con las características que había asumido su desarrollo a partir de 1870. El crecimiento del sector había comenzado tempranamente gracias a la alta protección acordada a la confección y a las tejedurías de punto. En el primer caso, se ha señalado que, entre 1870 y 1890, se produjo una fuerte sustitución de importaciones que fue alentada por el arribo de mano de obra calificada y acompañada de importantes cambios en la organización de la producción e innovaciones técnicas vinculadas con la introducción de la máquina de coser. ${ }^{7}$ Para 1914 , la industria de la confección estaba sólidamente arraigada; 7.081 establecimientos con una inversión superior a los 100 millones de pesos y 58.000 trabajadores empleados contrastaban con la situación de las hilanderías y tejedurías. Pocos años más tarde, un estudioso señalaba que el fomento del sector era una forma de protección social y moral que permitía "ayudar a la mujer para que pueda con el trabajo de la aguja sostener a la familia". 8

En la rama textil, el crecimiento había comenzado por las tejedurías de punto. Esta manufactura había nacido en la década de 1890, facilitada por la protección arancelaria, la depreciación monetaria y las bajas inversiones necesarias para su instalación. En contraste, el crecimiento de las hilanderías y tejedurías de algodón y lana fue un proceso muy lento y limitado. Si bien la Argentina era una gran exportadora mundial de lanas, la industrialización de la fibra no logró cobrar importancia. La crisis lanera de 1866 generó un movimiento a favor de la protección industrial que fue apoyado circunstancialmente por los terratenientes bonaerenses. Pero ello no se transmutó en una corriente de inversiones hacia el sector. La primera hilandería y tejeduría de paños de lana logró instalarse unos años más tarde a pesar del desinterés de los terratenientes para invertir capitales, para cerrar sus puertas en medio de grandes dificultades económicas en $1872 .{ }^{9}$

7 Chiaramonte, José. Nacionalismo y liberalismo económicos en la Argentina. Buenos Aires: Solar, 1970, p. 219-232; Sabato, Hilda y Romero, Luis Alberto. Los trabajadores de Buenos Aires. La experiencia del mercado, 1850-1880. Buenos Aires: Sudamericana, 1992, p. 66-70.

8 Cassegne Serres, Alberto. La política comercial argentina relacionada con las industrias nacionales. El cultivo algodonero y la industria hilandera. Buenos Aires: Compañía Sudamericana de Billetes de Banco, 1916, p. 107.

9 Sobre el movimiento proteccionista véase Chiaramonte, op. cit.; y Panettieri, José. Proteccionismo, liberalismo y desarrollo industrial. Buenos Aires: CEAL, 1983. 
La incorporación de la Argentina al comercio internacional mediante la especialización en la producción de granos y carnes, el incremento de la población y la fuerte urbanización que se produjo a partir de 1870, alentaron la demanda de textiles. El rubro más importante de consumo e importación eran los tejidos de algodón. La especialización del Lancashire en productos ordinarios permitió a Gran Bretaña conquistar rápidamente el nuevo mercado. El valor de las importaciones textiles argentinas superó a las de Chile en 1877, las de Estados Unidos en 1891 y las del Brasil en 1903. Para entonces la Argentina se convirtió en el principal mercado americano. ${ }^{10}$

La situación era algo diferente en el caso de los tejidos de lana donde los británicos debieron enfrentar la competencia de los fabricantes franceses y alemanes, que estaban especializados en la elaboración de tejidos de mejor calidad y diseño. ${ }^{11}$ A pesar de ello, hacia 1914, Inglaterra controlaba cerca del 50\% de las importaciones de hilados y tejidos de lana de la Argentina.

El estallido de la Primera Guerra Mundial supuso el inicio de una etapa de crecientes dificultades económicas y sociales. La Argentina se mantuvo neutral en el conflicto, pero ello no evitó que sufriera sus consecuencias. En primer término, la guerra perturbó el comercio internacional. La imposición de bloqueos, el encarecimiento de los fletes y la reducción de las bodegas disponibles impuso limitaciones muy fuertes al comercio. En el caso argentino, las restricciones se limitaron al comercio de importación, especialmente de combustibles, bienes intermedios y maquinarias. Junto a la caída de las importaciones, cesaron las inversiones extranjeras. Todo ello provocó dificultades financieras para el gobierno, cuyos ingresos dependían en gran medida de las importaciones. Con el fin de restablecer el equilibrio financiero, el gobierno impulsó una política fiscal ortodoxa que afectó el nivel de la producción y el empleo.

Por último, las expectativas generadas por el conflicto generaron una fuerte salida de oro, lo que condujo al gobierno, en agosto de 1914, a suspender la convertibilidad de la moneda. A partir de entonces y hasta 1921 la moneda local se apreció. En este contexto,

10 Farnie, Douglas. The English Cotton Industry and the World Market, 1815-1896. Oxford: Claredon Press, 1979, p. 95.

11 Jenkins, D. T. y Ponting, K. G. The British Wool Textile Industry, 1770-1914. London: Pasold Research Fund, 1982, p. 252-253. 
y en medio de una fuerte inflación internacional, se produjo una caída de los salarios reales y un incremento de los conflictos sociales. ${ }^{12}$

¿Cómo reaccionó la industria textil frente a esta coyuntura? La reducción de las importaciones fue importante en el rubro de los tejidos de lana cuya introducción descendió de un promedio anual de 4.300 toneladas entre 1911 y 1913, a unas 2.500 toneladas entre 1914 y 1917. En contraste, la introducción de telas de algodón descendió bastante menos; de 26.700 toneladas anuales en el trienio anterior a la guerra a 21.400 entre 1914 y 1917.

En este contexto, sólo la industria lanera se vio beneficiada por la nueva coyuntura. El descenso de las importaciones y el aumento de la demanda mundial de telas para los ejércitos permitieron a la industria local vivir un momento de auge. Algunas empresas, fundadas a finales del siglo XIX, como las hilanderías y tejedurías Campomar E Soulas y Luis Barolo y Cía. lograron colocar sus productos en el mercado internacional. Las exportaciones alcanzaron un record de 1.000 toneladas en 1915 para descender verticalmente. En realidad, la expansión industrial se vio limitada por la imposibilidad de importar maquinaria textil. ${ }^{13}$

Por su parte, la industria hilandera de algodón no tomó ninguna ventaja del conflicto. En 1914 la producción de fibra de algodón apenas superaba las 700 toneladas. Por entonces una sola hilandería de 7.000 husos instalados estaba en actividad. Al término de la guerra se le sumaron otras dos hilanderías (una en 1918 y otra en 1920) que hicieron duplicar los husos instalados. ${ }^{14}$ Pero, la producción local de hilados no superó las 1.000 toneladas hasta 1922. Sólo las tejedurías de punto parecen haber mejorado su situación gracias a que, precisamente, a partir de 1915, el abastecimiento de hilados y telas de algodón se normalizó.

En resumen, la Primera Guerra Mundial tuvo efectos disímiles entre las diferentes subramas: mientras la industria lanera y las

12 Cortés Conde, Roberto. La economía política de la Argentina en el siglo XX. Buenos Aires: Edhasa, 2005, p. 63. Véase también Pianetto, Ofelia. Mercado de trabajo y acción sindical en la Argentina, 1890-1922. Desarrollo Económico, n. 94, Buenos Aires, p. 297-307, 1984.

13 Garry, L. S. Textile markets of Argentina, Uruguay and Paraguay. Washington: Department of Commerce, Special Agents Series n. 164, 1920, p. 19-20.

14 Presumiblemente, las dos hilanderías instaladas en 1918 y 1920 eran las consignadas por el censo de 1914, que para entonces estaban paralizadas. Los datos sobre capacidad instalada fueron extraídos de Junta Nacional del Algodón, Boletín Mensual. 
tejedurías de punto se vieron beneficiadas por la reducción de las importaciones, la producción de hilados de algodón no logró sustituir importaciones. En este caso, el cese de la competencia externa fue muy breve y no existía una producción local de fibra de algodón en la cantidad y calidad necesarias para impulsara la industria hilandera.

\section{Importaciones, tarifas y tipo de cambio en la entreguerras}

A partir de 1918, el crecimiento de la industria textil se vio condicionado por los cambios que se produjeron en el nivel de la protección arancelaria y por los movimientos de los tipos de cambio, que alentaban o encarecían las importaciones. Desde 1876, la estructura de la tarifa aduanera se caracterizó por establecer altos gravámenes para la importación de confecciones y de tejidos de punto, mientras que la industria textil primaria (hilados y tejidos) recibió una protección notablemente menor. Hasta la sanción de la tarifa aduanera de 1906, el Congreso modificó anualmente (y en ocasiones de manera significativa) los derechos ad valorem. A partir de entonces, los niveles de derechos adquirieron cierta estabilidad. Como se observa en el Cuadro 2, durante el período de entreguerras, la estructura arancelaria mantuvo las características señaladas confiriendo un alto arancel ad valorem sobre los artículos acabados y fomentando la introducción de hilados de algodón y de lana. El derecho medio establecido para la importación de hilados de seda, no estaba dirigido a auspiciar el desarrollo de una industria local inexistente, sino a gravar materias primas para la elaboración de artículos que eran de consumo suntuario.

El impacto de la tarifa aduanera no queda debidamente expresado en los derechos establecidos. Por un lado, las fluctuaciones de los precios internacionales reducían su incidencia en la medida en que las autoridades argentinas no ajustaban los aforos sobre los cuales se calculaban los derechos. La discrepancia entre los valores de tarifa y los valores de mercado fue particularmente importante durante la Guerra y la posguerra. En 1920, los cálculos oficiales señalaban que la distancia entre ambos era del orden del $186 \%$ para el total de las importaciones, siendo el rubro de textiles donde se expresaba la mayor diferencia con un $244 \%{ }^{15}$

15 Dirección General de Estadística, Anuario de Comercio Exterior Argentino. Año 1920, p. 24. 
CUADRO 2

Evolución de la tarifa aduanera (\% ad valorem), 1905-1935

\begin{tabular}{|l|c|c|c|c|c|c|c|c|}
\hline Artículo & $\mathbf{1 9 0 5}$ & $\mathbf{1 9 1 1}$ & $\mathbf{1 9 1 8}$ & $\mathbf{1 9 2 0}$ & $\mathbf{1 9 2 5}$ & $\mathbf{1 9 2 8}$ & $\mathbf{1 9 3 1}$ & $\mathbf{1 9 3 5}$ \\
\hline Ropa & 40 & 40 & 47 & 47 & 40 & 50 & 50 & 57 \\
\hline $\begin{array}{l}\text { Telas de } \\
\text { seda }\end{array}$ & 40 & 42 & 47 & 47 & 47 & 40 & 23,5 & 23,5 \\
\hline $\begin{array}{l}\text { Telas de } \\
\text { algodón }\end{array}$ & 25 & 25 & 25 & 22 & 25 & 22 & 25 & 32 \\
\hline $\begin{array}{l}\text { Telas de } \\
\text { lana }\end{array}$ & 30 & 30 & 37 & 37 & 30 & 32 & 30 & 37 \\
\hline $\begin{array}{l}\text { Hilados } \\
\text { seda }\end{array}$ & 25 & 25 & 32 & 32 & 25 & 10 & 12 & $12 *$ \\
\hline $\begin{array}{l}\text { Hilados } \\
\text { algodón }\end{array}$ & 5 & 5 & 7 & 7 & 5 & 5 & 10 & 12 \\
\hline $\begin{array}{l}\text { Hilados } \\
\text { lana }\end{array}$ & 5 & 5 & 7 & 7 & 5 & 5 & 10 & 12 \\
\hline
\end{tabular}

FUENTE: Elaboración propia en base a Vicente Vázquez Presedo. El caso argentino. Buenos Aires: Eudeba, 1978; y Anuario de Comercio Exterior, 1918-35.

* Se creó una partida especial para el rayón con un aforo $66 \%$ menor.

La desactualización de los aforos no sólo perjudicaba a la industria local sino que también afectaba la recaudación aduanera. En diciembre de 1920, el presidente Hipólito Yrigoyen dispuso un incremento del $20 \%$ en los aforos mediante la ley 11.022 , lo que coincidió con el inicio de una tendencia a la caída de los precios internacionales. Tres años más tarde, el segundo gobierno radical volvió a incrementar los aforos, disponiendo un aumento del $40 \%$ adicional sobre el aumento de 1920.

En 1923 cobró mayor fuerza un movimiento proteccionista que era auspiciado por el ministro de Hacienda Rafael Herrera Vegas. Entonces, se conformaron varias comisiones de estudio entre empresarios y funcionarios públicos, para definir reformas destinadas a impulsar la industria. Poco después, esta iniciativa quedó trunca cuando el presidente Marcelo de Alvear despidió a su ministro y lo reemplazó por un notorio liberal.

El flujo de las importaciones también se vio modificado por la variación en los tipos de cambio. Entre 1920 y 1923, la moneda se depreció un $40 \%$ compensando el atraso de los aforos. Pero, a partir de ese momento se inició un lento proceso de apreciación que alcanzó el 12\% hacia 1927. La apreciación de la moneda parece haber perju- 
dicado a la industria de modo que se multiplicaron los pedidos de los empresarios textiles tendientes a lograr una mayor protección.

En conjunto, durante los años veinte, la introducción de textiles se mantuvo como el principal componente del comercio importador. Su participación en el valor total de las importaciones no descendió por debajo del 22\%. El nivel máximo se alcanzó en 1918 y 1919 (33\%) cuando todavía existían grandes dificultades para importar otros productos, mientras que el nivel mínimo se registró entre 1926 y 1927 con un $22 \%$.

Otro comportamiento relevante fue que las importaciones de textiles no acompañaron la caída del conjunto de las importaciones durante la crisis de 1929. Como consecuencia de ello, su participación en el valor total de las importaciones alcanzó al 33\% en 1932. En resumen, durante la década de 1920, la Argentina continuó siendo una gran importadora de artículos textiles.

Los años treinta implicaron serias restricciones al comercio internacional. La caída del valor y del monto de las exportaciones impuso restricciones a la adquisición de productos en el exterior. La devaluación monetaria de 1931, que fue del orden del 40\%, acentuó la caída de las importaciones, aunque este efecto se vio compensado por las devaluaciones aplicadas por los socios comerciales del país. La dictadura surgida del golpe de estado del 6 de septiembre de 1930 también elevó los aranceles para varias partidas de tejidos. El decreto 39 del 25 de febrero de 1931 estableció un derecho ad valorem del $30 \%$ para los tejidos de lana, un $25 \%$ para los de algodón, en tanto que los hilados de lana y algodón fueron elevados hasta el 10\%. ${ }^{16}$ A estos derechos se sumó el adicional del $10 \%$ dispuesto como un derecho de emergencia para todas las importaciones y destinado a paliar la crisis de las finanzas estatales.

La caída de los precios internacionales de la lana y el algodón, y la reducción de la competencia externa provocada por el incremento de los aranceles, las restricciones cambiarias y la devaluación de la moneda estimularon la sustitución de importaciones.

El control de cambios fue utilizado principalmente para corregir el desequilibrio externo con el área del dólar a través del desvío de las importaciones hacia el área de la libra esterlina. Como consecuencia de ello, las importaciones más competitivas en precio quedaron temporalmente excluidas del mercado local. ${ }^{17}$ Como en

16 Revista de la Unión Industrial Argentina, n. 747, marzo de 1931, p. 41.

17 Prados Arrarte, Jesús. El control de cambios en la Argentina. Buenos Aires: 1944, p. 94. 
otras industrias, las restricciones cambiarias estimularon la radicación de firmas norteamericanas que comenzaron a producir bienes que antes se importaban. Entre 1931 y 1943 al menos siete grandes empresas textiles se instalaron en el país. ${ }^{18}$ Al estímulo del control cambiario se sumó la depreciación del tipo de cambio real durante la década de 1930 lo que encareció las importaciones. Sin embargo, debe tenerse en cuenta que estos efectos eran un subproducto de las políticas que no estaban encaminadas a fomentar al sector.

En 1933, los empresarios textiles enfrentaron con éxito las negociaciones arancelarias con Gran Bretaña en el marco de lo que sería el tratado Roca-Runciman. Para los negociadores británicos una rebaja en los aranceles del rubro textiles era clave dado que la industria británica no podía competir con iguales ventajas en otros rubros del comercio de importación como los automóviles y la maquinaria. El gobierno conservador del general Agustín Justo convocó a un grupo de empresarios, liderados por Ernesto Herbín, quienes tuvieron la tarea de asesorar a los negociadores argentinos. Dado que Gran Bretaña no ofreció grandes ventajas comerciales a la Argentina, la posición negociadora del gobierno argentino se endureció. Como se observa en el Cuadro 2, no sólo no se produjeron grandes rebajas arancelarias sino que en algunos rubros hubo incrementos.

\section{Avances y retrocesos: la industria textil entre 1914 y 1933}

En este apartado nos proponemos evaluar el desempeño del sector textil durante los años veinte y los primeros años de la década de 1930. Para ello combinaremos diversas informaciones sobre capitales invertidos, número de establecimientos, producción, importaciones y otras de carácter cualitativo.

$\mathrm{Al}$ intentar evaluar la evolución de la industria durante los años veinte nos encontramos con la ausencia de estadísticas oficiales. El censo industrial de 1935, no es estrictamente comparable con el de 1914. Además, a mediados de los años treinta, la rama textil había sufrido una gran transformación vinculada con la aceleración de la sustitución de importaciones posterior a 1930. Es decir muestra una realidad distinta a la de finales de los años veinte.

18 Villanueva, op. cit., p. 464. 
Una primera aproximación a esta problemática puede realizarse mediante la comparación de las inversiones entre 1914 y 1933, año en que la Confederación Argentina de Industrias Textiles, entidad constituida en 1932, realizó un primer relevamiento. Como se observa en el Gráfico 1, entre 1914 y 1933, se produjo un fuerte incremento del capital invertido en la industria textil (344\%). En el nivel de las subramas el aumento fue liderado por la industria de la seda (inexistente en 1914), la hilandería y tejeduría de algodón (897\%), las tejedurías de punto (537\%) y la hilandería y tejeduría de lana $(414 \%)$.

Los grandes incrementos en las inversiones en la industria algodonera y en la lanera, principales subramas textiles, revelan el enorme campo existente para sustituir importaciones. La corriente inversora que se dirigió a la rama en la década de 1920, no transformó el predominio de la industria lanera y las tejedurías de punto sobre el sector. A pesar del notable incremento de la participación de la subrama algodonera, que pasó del 10\% al 22\%, no superó el valor de los capitales invertidos en la industria lanera y las tejedurías de punto que ascendieron desde el $29 \%$ y el $27 \%$, al $34 \%$ y al $28 \%$ respectivamente.

\section{GRÁFICO 1}

Capitales invertidos en las diversas industrias textiles en 1914 y 1933 (en u\$s)

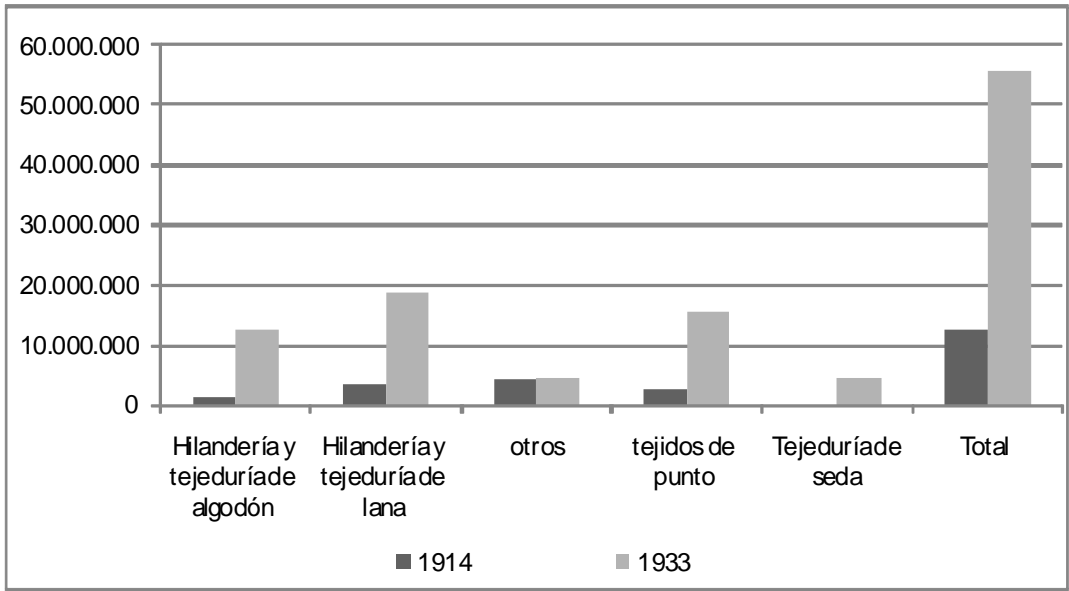

FUENTE: elaboración propia en base a Tercer Censo Nacional y Confederación Argentina de Industrias Textiles. La industria textil argentina. Buenos Aires: 1934. El tipo de cambio fue tomado de Anuario Geográfico Argentino. Buenos Aires, 1941. 
El renglón más importante del consumo interno era el algodonero. El Cuadro 3 contiene las cifras de importaciones de textiles de algodón en años seleccionados. Se observa que, en los rubros de hilados y tejidos en piezas, el monto de las importaciones no disminuyó hasta la crisis de 1929.

\section{CUADRO 3}

Evolución de las importaciones de textiles de algodón, 1919-1935 (en toneladas)

\begin{tabular}{|l|c|c|c|c|c|c|c|c|c|}
\hline \multicolumn{1}{|c|}{ Rubros } & $\mathbf{1 9 1 9}$ & $\mathbf{1 9 2 1}$ & $\mathbf{1 9 2 3}$ & $\mathbf{1 9 2 5}$ & $\mathbf{1 9 2 7}$ & $\mathbf{1 9 2 9}$ & $\mathbf{1 9 3 1}$ & $\mathbf{1 9 3 3}$ & $\mathbf{1 9 3 5}$ \\
\hline Hilados & 6.273 & 6.367 & 8.019 & 8.200 & 10.489 & 10.942 & 7.137 & 9.217 & 6.645 \\
\hline $\begin{array}{l}\text { Tejidos en } \\
\text { piezas }\end{array}$ & 26.445 & 23.785 & 35.543 & 35.747 & 31.638 & 38.708 & 24.470 & 30.260 & 34.334 \\
\hline $\begin{array}{l}\text { Tejidos en } \\
\text { otras } \\
\text { formas* }\end{array}$ & 1.413 & 1.877 & 3.590 & 2.261 & 2.948 & 2.280 & 916 & 647 & 345 \\
\hline $\begin{array}{l}\text { Tejidos de } \\
\text { punto y } \\
\text { otras con- } \\
\text { fecciones** }\end{array}$ & 1.020 & 588 & 1.261 & 741 & 480 & 229 & 99 & 70 & 55 \\
\hline
\end{tabular}

FUENTE: Elaboración propia en base a Anuario de Comercio Exterior Argentino, años 1919-1935.

* Se incluyen colchas, cortinas, frazadas, pañuelos, toallas, manteles y servilletas.

** Se incluyen guantes, medias, fajas, ponchos y tapados.

Durante los años veinte, la industria hilandera de algodón logró algunos avances significativos en cuanto al incremento de su participación en el total del consumo interno que ascendió desde una cifra insignificante hasta el $25 \%$ para mediados de la década. Este proceso estaba impulsado por un número limitado de empresas laneras como Luis Barolo y Cía. (luego Piccaluga), Campomar \& Soulas y Ángel Braceras, entre otras. A ellas se les sumaron otras firmas de mayor peso como Fábrica Argentina de Alpargatas, Manufactura Algodonera Argentina y la Compañía General de Fósforos. Estas empresas intentaban satisfacer sus necesidades vinculadas a la fabricación de lonas, alpargatas o fósforos. En la mayoría de los casos, esta integración vertical no permitió a las empresas independizarse de las importaciones ya que las calidades del algodón argentino no permitían la fabricación de hilados de todos los títulos. En este sentido, debe recordarse que la expansión 
del cultivo de algodón estaba orientada fundamentalmente al mercado externo. ${ }^{19}$

CUADRO 4

Producción e importaciones de hilados de algodón, 1919-1935 (en toneladas)

\begin{tabular}{|l|c|c|c|c|c|c|c|c|c|}
\hline & $\mathbf{1 9 1 9}$ & $\mathbf{1 9 2 1}$ & $\mathbf{1 9 2 3}$ & $\mathbf{1 9 2 5}$ & $\mathbf{1 9 2 7}$ & $\mathbf{1 9 2 9}$ & $\mathbf{1 9 3 1}$ & $\mathbf{1 9 3 3}$ & $\mathbf{1 9 3 5}$ \\
\hline Importación & 6.273 & 6.367 & 8.019 & 8.200 & 10.489 & 10.942 & 7.137 & 9.217 & 6.645 \\
\hline Producción & 457 & 938 & 1.292 & 2.624 & 3.488 & 4.052 & 5.023 & 8.177 & 15.897 \\
\hline $\begin{array}{l}\text { Consumo } \\
\text { aparente }\end{array}$ & 6.730 & 7.305 & 9.311 & 10.824 & 13.977 & 14.994 & 12.160 & 17.394 & 22.542 \\
\hline $\begin{array}{l}\text { Producción/ } \\
\text { consumo }\end{array}$ & $7 \%$ & $13 \%$ & $14 \%$ & $24 \%$ & $25 \%$ & $27 \%$ & $41 \%$ & $47 \%$ & $71 \%$ \\
\hline
\end{tabular}

FUENTE: Elaboración propia en base a Junta Nacional del Algodón, Boletín Mensual y Anuario de Comercio exterior Argentino, 1919-1935.

A partir de 1929, la caída del precio internacional de algodón, la maduración del cultivo algodonero en el Chaco y las dificultades para importar alentaron una industrialización local. Como respuesta a estas condiciones, el número de hilanderías trepó de cinco en 1930 a siete en 1933 y, dos años más tarde, 18. Los husos instalados ascendieron un 300\% trepando desde 52.400 en 1930 hasta poco más 214.000 en 1935. El promedio de husos por establecimiento se mantuvo en torno de los 10.000, que era muy modesto para la escala internacional.

En relación con las importaciones de tejidos en piezas puede describirse una evolución similar. En cambio, como se observa en el Cuadro 3, la evolución de las importaciones de tejidos en otras formas y de tejidos de punto y otras confecciones muestra una tendencia decreciente desde mediados de los años veinte. Esto se explica por el desarrollo de la industria local gracias al incremento de la protección aduanera y al aumento del consumo nacional. En 1923, la Cámara de Comercio de Estados Unidos señaló el notable progreso de las fábricas textiles; desde hacía una década se multiplicaban las inversiones en el sector y algunos talleres se convertían en grandes fábricas. ${ }^{20}$ Para el final de la década, la industria ya abastecía la demanda interna.

19 Sobre el tema véase Donna Guy. El rey del algodón. Los Estados Unidos, la Argentina y el desarrollo de la industria algodonera argentina. Mundo Agrario, n. 1, 2000, en www.mundoagrario.unlp.edu.ar

20 A rgentine Textile Mills Growing Rapidly. Comments on Argentine Trade, vol. II, April 1923, p. 41. 
Las tendencias observadas para las importaciones de hilados y tejidos de algodón no pueden verificarse para los artículos de lana (véase Cuadro 5). Las importaciones de hilados y tejidos de lana mostraron una fuerte inestabilidad, pero no se aprecia una tendencia declinante durante los años veinte. Las mayores importaciones de hilados y tejidos se alcanzaron en 1929. A partir de entonces, la caída fue general para todos los tipos de artículos. En 1930, la industria local tenía instalados unos 80.000 husos y cerca de 2.000 telares. Para 1933 existían cerca de treinta fábricas textiles de lana, de las cuales 27 tenían integradas las fases de hilado y el tejido. El personal empleado alcanzaba unos 10.000 trabajadores pero Campomar \& Soulas y Piccaluga E Cía ocupaban aproximadamente el $60 \%$ de la mano de obra empleada mientras que diez firmas tenían menos de 50 empleados cada una. ${ }^{21}$ La industria tejedora y la fabricación de tejidos de punto estaba ya sólidamente instalada, pero la calidad de la materia prima local limitaba los rubros de producción:

Es opinión de los principales tejedores del país, que en los renglones de tejidos gruesos, franelas, ponchos, mantas y otros secundarios ya no existe peligro de competencia de parte del extranjero, ya que en el país se produce lo necesario para cubrir la totalidad de sus necesidades, y que los aventajamos en calidades y precios (...). No pasa lo mismo en el artículo fino, es decir paños para militares y encardados de alta calidad. ${ }^{22}$

La crisis de 1929 terminó por consolidar la expansión del sector. Para 1935, el número de husos instalados era de 146.509 (88.000 para cardado y 58.000 peinado), lo que representaba un incremento del $83 \%$ con respecto a 1930 . En el mismo período, el número de telares creció un 23\%, alcanzando a unos 2.462. En 1935, las importaciones de hilados de lana sólo representaron un 9\% del consumo total del país en tanto que las de tejidos de lana o mezcla superaron el $30 \%$.

Una caso diferente fue el de la industria de la seda. Desde principios del siglo $X X$, el mercado para este tipo de productos se vio estimulado debido a los cambios en la moda femenina que implicaron el acortamiento de las faldas y una demanda de medias de mayor calidad. Durante la posguerra, la difusión del rayón

21 Confederación Argentina de Industrias Textiles, op. cit., p. 129.

22 Santiago Selvini. Industrialización de la lana. 1931, p. 17 (mimeo). 
alentó aún más la demanda dado que su costo era notablemente menor que la seda natural. ${ }^{23}$

\section{CUADRO 5}

Evolución de las importaciones de textiles de lana, 1919-1935 (en toneladas)

\begin{tabular}{|l|c|c|c|c|c|c|c|c|c|}
\hline \multicolumn{1}{|c|}{ Rubros } & $\mathbf{1 9 1 9}$ & $\mathbf{1 9 2 1}$ & $\mathbf{1 9 2 3}$ & $\mathbf{1 9 2 5}$ & $\mathbf{1 9 2 7}$ & $\mathbf{1 9 2 9}$ & $\mathbf{1 9 3 1}$ & $\mathbf{1 9 3 3}$ & $\mathbf{1 9 3 5}$ \\
\hline Hilados & 50 & 427 & 1.003 & 1.062 & 1.085 & 1.828 & 953 & 974 & 694 \\
\hline $\begin{array}{l}\text { Tejidos en } \\
\text { piezas }\end{array}$ & 2.002 & 3.250 & 3.868 & 4.183 & 4.573 & 5.138 & 3.166 & 2.787 & 2.880 \\
\hline $\begin{array}{l}\text { Tejidos en } \\
\text { otras formas }\end{array}$ & 299 & 463 & 455 & 396 & 410 & 451 & 291 & 51 & 96 \\
\hline $\begin{array}{l}\text { Tejidos de } \\
\text { punto y otras } \\
\text { confecciones** }\end{array}$ & 20 & 47 & 78 & 75 & 52 & 169 & 84 & 36 & 64 \\
\hline
\end{tabular}

FUENTE: Elaboración propia en base a Anuario de Comercio Exterior Argentino, años 1919-1935.

* Se incluyen colchas, cortinas, frazadas, pañuelos, toallas, manteles y servilletas.

* Se incluyen artículos manufacturados, guantes, medias y ponchos.

La tarifa aduanera no distinguió hasta 1933 los tejidos de rayón de los de seda natural. Los altos derechos ad valorem (47\%) establecidos para la introducción de telas de seda natural y el hecho de que esos derechos se liquidaran sobre un aforo muy superior al precio de mercado de los tejidos de rayón, alentó la inversión en tejedurías. La primera fábrica de tejidos de seda artificial, Sedalana, fue instalada en 1925 por capitales alemanes. Paradójicamente, las fallas del arancel de 1906 y los infructuosos intentos por modificarlo reservaron el mercado en este caso para la industria local.

Además, la inversión en las tejedurías se vio estimulada por una serie de innovaciones en la tecnología de producción que abarataron los costos de instalación. Este factor, alentó el surgimiento pequeños talleres que a menudo empleaban solo mano de obra familiar. La combinación de un mercado protegido, una demanda ascendente y bajos requerimientos de capital impulsaron la sustitución de importaciones de manera que ya en 1928 la industria local abastecía el 50\% del mercado. La expansión continuó

23 Sobre el desarrollo de la industria del rayón véase Chandler, Alfred. Escala y diversificación. Zaragoza: Prensas Universitarias de Zaragoza, 1996, vol. 1, p. 494-502. 
en los años treinta. En 1937, un informe del sector industrial aseguraba que el tejido de seda y mezcla "se ha popularizado hasta tal punto que ya no es más un artículo de lujo y se halla al alcance de las clases más modestas de la población". ${ }^{24}$

CUADRO 6

Producción e importación de tejidos de seda artificial,

1925-1934 (en toneladas)

\begin{tabular}{|l|c|c|c|c|c|c|c|c|c|c|}
\hline \multicolumn{1}{|c|}{ Años } & $\mathbf{1 9 2 5}$ & $\mathbf{1 9 2 6}$ & $\mathbf{1 9 2 7}$ & $\mathbf{1 9 2 8}$ & $\mathbf{1 9 2 9}$ & $\mathbf{1 9 3 0}$ & $\mathbf{1 9 3 1}$ & $\mathbf{1 9 3 2}$ & $\mathbf{1 9 3 3}$ & $\mathbf{1 9 3 4}$ \\
\hline Producción & 140 & 213 & 297 & 439 & 496 & 528 & 567 & 848 & 1.426 & 2.398 \\
\hline Importación & 395 & 451 & 428 & 420 & 338 & 521 & 699 & 420 & 382 & 110 \\
\hline $\begin{array}{l}\text { Consumo } \\
\text { aparente }\end{array}$ & 535 & 664 & 725 & 859 & 834 & 1.049 & 1.266 & 1.268 & 1.808 & 2.508 \\
\hline $\begin{array}{l}\text { Producción/ } \\
\text { Consumo }\end{array}$ & $26 \%$ & $32 \%$ & $41 \%$ & $51 \%$ & $59 \%$ & $50 \%$ & $45 \%$ & $67 \%$ & $79 \%$ & $96 \%$ \\
\hline
\end{tabular}

FUENTE: Elaboración propia en base a Manuel Oliva, La industria de la seda en la Argentina. Buenos Aires, 1937.

En contraste, la elaboración de hilados de rayón no se inició durante el período bajo estudio. En este caso, los requerimientos de capital y la complejidad de la tecnología de producción inhibieron el surgimiento de esta industria. Sólo en 1935 como respuesta a las trabas a las importaciones se instalaría Rhodiaseta, del grupo francés Rhone Poulec, a la que se sumaría el anglo norteamericana Ducilo en $1937 .^{25}$

En conjunto, hacia 1935 el avance de la industria textil quedó reflejado en el censo industrial de ese año. Entre 1914 y 1935, el personal empleado se había elevado en un $67 \%$ en tanto que la potencia instalada había crecido un $488 \%$. Por entonces, la industria textil lideraba el crecimiento industrial. Si bien la Gran Depresión había acelerado ese crecimiento, el censo reveló el peso de los cambios ocurridos en la década de 1920. El 34\% de las fábricas existentes habían sido fundadas en los años veinte. Ellas ocupaban el $27 \%$ del personal empleado y contribuían con $28 \%$ de la producción. ${ }^{26}$

24 Oliva, op. cit., p. 15.

25 Belini, Claudio. La Industria durante el primer peronismo. Un análisis de las políticas públicas y de su impacto. Tesis de Doctorado, Universidad de Buenos Aires, 2004, vol. 2, p. 608-609.

26 Censo Industrial de 1935. Buenos Aires, 1938, p. 37 y p. 129. 


\section{Consideraciones finales}

En 1914, la Argentina satisfacía su demanda en forma predominante con textiles importados, inclusive en el renglón de artículos de lana a pesar de que el país era el tercer productor mundial. A partir de entonces, esta situación comenzó a modificarse. Especialmente importante fue el crecimiento de la producción de tejidos de punto de algodón y lana que logró sustituir las importaciones con anterioridad a 1929. Por su parte, las fábricas de tejidos de lana y rayón lograron cubrir más del 50\% de la demanda local hacia finales de la década de 1920.

Con todo, el lento avance de la industria algodonera, quedó reflejado en el importante peso que conservaron las importaciones de textiles hasta el final de los años veinte, representando el 25\% del total del valor de las importaciones argentinas.

A partir de la Gran Depresión, se observa una tendencia a la disminución de las importaciones y al incremento de la producción nacional. Algunas evidencias sobre la capacidad de producción de la industria local en 1930 y su contraste con los resultados del censo de 1935 indican que fue en esos años cuando se acentuó la sustitución. Este punto, señalado para la industria algodonera por Petrecolla, también puede sostenerse para la rama lanera, que reconocía un origen más antiguo.

Al menos en parte, los problemas de crecimiento industrial parecen estar vinculados con el problema aduanero. Durante la década de 1920 se mantuvo la estructura tarifaria que alentaba la importación de hilados y tejidos y protegía la fabricación local de tejidos de punto y de confecciones. Sin embargo, la cuestión arancelaria no era el único problema que debía enfrentar la industria. Otras dificultades, que sólo podrán constatarse a partir de estudios de carácter microeconómico, residían en los costos de producción (especialmente los salarios) y la disponibilidad y calidad de las materias primas locales como el algodón y la lana. 